\title{
Evaluating the Creditworthiness of a Client in the Insurance Industry Using Adaptive Neuro-Fuzzy Inference System
}

\author{
Radek Doskocil \\ Brno University of Technology \\ Kolejní 2906/4, 61200, Brno, Czech Republic \\ E-mail.doskocil@fbm.vutbr.cz.
}

cross $^{r e f} \underline{\text { http://dx.doi.org/10.5755/j01.ee.28.1.14194 }}$

The article deals with the issue of a client's creditworthiness assessment in the insurance industry. The article aims to identify new factors related to a client's creditworthiness, and to create an assessment model. The factors which have relations to a client's creditworthiness were identified in the first research stage. These factors represent the inputs into the model. The assessment model of the client's creditworthiness was created in the second stage. In the third stage, the model was verified and implemented. The neuro-fuzzy method was used for creation, verification and implementation of the model. Five variables were selected as the inputs including damages, insurance length, insurance penetration, annual earnings and $2^{\text {nd }}$ degree liquidity. These input variables were divided into two categories based on their nature (insurance indicators, accounting indicators). Research results show that the proposed model was verified above input data and can be used as a tool for supporting decisions concerning a client's creditworthiness in the insurance industry. The main contribution of the paper is the identification of new factors which have relation to a client's creditworthiness and the creation of the assessment model which works with these new factors transferred to fuzzy variables. The proposed model differs from the current approaches primarily thanks to its complex, systematic and hierarchical ability to evaluate the newly identified factors related to a client's creditworthiness as fuzzy variables. Thanks to the model, it is possible to automate and accelerate the process of evaluation of a client's creditworthiness in the insurance industry. The knowledge gained from the evaluation model is immediately possible to use in the strategic management of insurance companies e.g. in marketing activities.

Keywords: Insurance Industry, Creditworthiness, Decision-Making, Neuro-Fuzzy Model, Fuzzy Logic, Artificial Neural Network.

\section{Introduction}

The insurance industry (Biener, Eling \& Wirfs, 2016), as one of the segments of national economy, currently ranks among significant sectors and represents an indispensable part of the modern society (Ma, 2015). By its nature, it is involved in all economic activities (Bertola \& Koeniger, 2015), affects market economy and mediates the creation of new job opportunities (Kwon, 2014). It provides one of the possible responses to risk both to businesses and individuals (Xuan, Meng \& Dongli, 2010). Risk, or business risk, is a factor directly connected to business (Wu, Olson \& Dolgui, 2015).

The insurance market (Alhassan \& Biekpe, 2015; Armeanu, Istudor, Florinel, \& Burca, 2014; Eling \& Schmit, 2012 ) is a place where the supply and demand for protection in the form of insurance meet. There has been a long-term dominance of supply over demand in the market, which results in increasing competition among individual insurance companies (Hendrych \& Cipra, 2015; Witkowska \& Lakstutiene, 2014). This competition affects the attitude of insurance companies to their existing as well as prospective clients (Berry-Stoelzle, Hoyt \& Wende, 2013). It is common these days to apply individual approach to each client, which eventually calls for the necessity of continuous creditworthiness identification (Ulbinaite, Kucinskiene, \& Le Moullec, 2013; Stepchenko \& Voronova, 2015). The process of identification of a client's creditworthiness thus ranks among the fundamental managerial decision-making processes of each insurance company, in particular due to the fact that this very process affects the net income of the given insurance company.

The main aim of the article is to identify new factors related to a client's creditworthiness and to propose an evaluation model of creditworthiness in the insurance industry. The model will use a combined system in the form of a neuro-fuzzy system (artificial neural network - fuzzy logic).

\section{Problem Analysis}

Most insurance companies only check creditworthiness of existing clients. Prospective clients are, in general, considered creditworthy. Only in case of client's negative signals to the insurance company is the client's creditworthiness analyzed. The analysis focuses primarily on the evaluation of client's importance for the insurance company. A creditworthy client is a client who brings in more financial means to the insurance company than they draw in indemnity. The analysis of finding out about a client's creditworthiness includes evaluation of the client from the following aspects:

- Damages - the proportion of damages paid out and the insurance payments paid to the insurance company. It is a very important factor for assessing a client's creditworthiness. The higher the value of damages, the worse the creditworthiness is and vice versa. In practice, the recommended maximum value of damages is up to $75 \%$. If above this value, the client is not attractive for the insurance 
company, their creditworthiness is low, and the client may me even refused, in an extreme case. The value of $75 \%$ is increased by at least $20 \%$ of administrative costs (i.e. all costs related to the administration of insurance policies, and in particular, to the signing of the insurance policies, including commissions paid to agents), which explains the maximum percentage of $75 \%$.

- Payment discipline - historical view of repaying insurance premium. If the premium is not paid, the insurance policy is cancelled, pursuant to the applicable law, within a period stipulated by law.

- Insurance penetration - the number of insured risks out of all real risks.

So-called "client's profitability" is determined by assessing all the mentioned factors. Profitability means assessment of strengths and weaknesses, based in most cases on the assessor's subjective views. Profitability is in practice represented by a T-shaped scheme, where client's strengths are grouped on the one side and weaknesses on the other side. A client's creditworthiness is defined by mere adding up or assessing both sides, a process in which the assessor's hands-on experience in the field and their other skills and abilities play a crucial role.

A client's creditworthiness is most often analyzed on the ground of a debt relief decision. The authority concerning the eligibility for debt relief is defined by the amount of the debt. Debts of up to a certain amount may be decided by employees at different levels of the insurance company.

The rough set theory was introduced to obtain knowledge rules for a client's creditworthiness. Attributes such as type of a company, the length of insurance, insurance penetration, damages (percent) and liquidity ( $2^{\text {nd }}$ degree) were combined to build a decision table. After unification (discretization and categorization) of input value attributes, decision-making rules were calculated through the decision-making rule generation algorithm based on the rough set theory. Classification based on the generated rules classified the client into creditworthy and un-creditworthy groups. The high accuracy of creditworthy based on the rough set theory demonstrated that this method was effective for a client creditworthiness (Doskocil \& Doubravsky, 2014).

The aim of the research by Doubravsky and Doskocil is to present an approach of how to identify the profitability of a client in the insurance business under the condition of input data uncertainty. The solution to the decision-making problem is based on the decision to extend or renew an insurance contract for the next period (specifically two years). The solution to this problem is based on the decisionmaking task, which is graphically illustrated by a decision tree. This decision problem is solved for a fictitious client, but the necessary data sets are based on real data sets. The case study is represented by a tree with three lotteries, three decisions and seven terminals. The results arising from the paper serve mainly the needs of insurance companies. The main contribution of this paper is using a decision tree to provide managers with the tool to support decision-making in evaluating whether an insurance policy of a given client may be extended or not in the next period, and information about expected profitability for the next period and its confidence interval (Doubravsky \& Doskocil, 2016; Doskocil \& Doubravsky, 2015).
Other articles published in internationally recognized databases WoS or Scopus, or papers delivered and published at international conferences discuss creditworthiness in the insurance industry from the client's point of view only, which means that the outcome of assessment is primarily designed for a client's needs, as a prospective buyer of the insurance policy. Therefore, articles deal with different approaches to the assessment of creditworthiness of an insurance company as a whole. Selected articles, which may be used for assessing a client's creditworthiness, are introduced below. The research by Chiet et al. presents an artificial neural network as a tool designed to create an insolvency predictive model for Malaysian insurance companies. The model could predict any future failure of a general insurance company. The research results show high predictability by means of artificial neural networks. It increases the usefulness of this method as tools for support of prediction future insurer's insolvency in Malaysia (Chiet, Jaaman, Ismail \& Shamsuddin, 2009).

This study of authors Brockett et al. presents a comparison of neural network, statistical / mathematical methods, and variable choice for life insurers' financial distress prediction. The models considered are two artificial neural network methods (back propagation - BP and learning vector quantization - LVQ) and two more standard statistical methods (multiple discriminant analysis and logistic regression analysis). The research results show that the BP and LVQ outperform the traditional statistical approaches (Brockett, Golden, Jang \& Yang, 2006).

The research by Brockett et al. describes an artificial neural network model as part of an early warning system for predicting an insurer's insolvency. The research results show high predictability and generalisability of results for the purpose of insolvency prediction. It shows that artificial neural networks could by applied as a useful tool for this and other purposes (Brockett, Cooper, Golden, \& Xia, 1997).

The research by Shuang and Wei presents the Back Propagation (BP) neural network model to the solvency early-warning system for life insurance, and improved the traditional BP algorithm. They used the improved BP neural network to predict the solvency of Life Insurance Company. The research results show that the prediction of improved BP neural network has higher accuracy and sensitivity to early warning signals to provide reference for life insurance companies and insurance regulators, compared with the traditional BP neural network (Shuang \& Wei, 2011).

\section{Theoretical Background}

Neuro-fuzzy systems are soft computing methods that combine different ways of artificial neural networks and fuzzy concepts. A special kind of artificial neural network based on Takagi-Sugeno fuzzy inference system is called Adaptive Network Fuzzy Inference System - ANFIS (Gocic, Motamedi, Shamshirband, Petkovic, \& Hashim, 2015; Nikolic et al., 2016). The Fuzzy Logic Toolbox in MATLAB software is designed for this ANFIS Editor method (Ayesh \& Blewitt, 2015).

The principle of operation of artificial neural networks (Palavar, Ozyurek, \& Kalyon, 2015) can be the best described using an analogy with human thinking. We talk about a "Black box". What is happening in this "Black box" 
we know only vaguely. The human brains are interconnected by billions of neurons. Electro-chemical reactions occur between the neurons. Similar activities are simulated by artificial neural networks. Before the artificial neural network is used, it must first be learnt on real data. The inputs for an artificial neural network is a matrix of values (input and output variables), which represents individual cases with their specific parameters. Calculation sets the links between neurons in their weight. The principle of the method therefore consists in adjusting the weights, which are determined by the deviation of calculated outputs from the facts. Correction of weights is performed on the basis of these deviations. It is an iterative optimization process, which minimizes the sum of squared deviation. As the learning stage ends, the testing stage starts. This stage tests the quality of the learning process which tests the acquired knowledge of artificial neural network on simple examples. The aim of this stage is to detect differences between the calculated results and real results. The learning and testing processes are repeated until the error is minimal. Afterwards, a successful artificial neural network can be used for solving specific problems.

A fuzzy set is a set whose elements have degrees of membership. The fuzzy set was introduced by Lotfi A. Zadeh in 1965 as an extension of the classical notion of sets and can be applied in many fields of human activity (L. A. Zadeh, 1965). The degree of membership to fuzzy sets determines "how much" the element belongs to the set. This is the basic principle of fuzzy sets. A fuzzy set is defined as follows: Let $X$ be a non-empty set and $\mu_{\widetilde{A}}: X \rightarrow[0 ; 1]$. Then fuzzy set $\widetilde{A}$ is a set of all ordered pairs $\left(\mathrm{x}, \mu_{\mathrm{A}}(\mathrm{x})\right)$ therefore $\widetilde{\mathrm{A}}=\left\{\left(\mathrm{x}, \mu_{\widetilde{\mathrm{A}}}(\mathrm{x})\right): \mathrm{x} \in \mathrm{X}, \mu_{\widetilde{\mathrm{A}}}(\mathrm{x}) \in[0 ; 1]\right\}$.

A fuzzy logic measures the certainty or uncertainty of how much the element belongs to the set (Lotfi A. Zadeh, 2007). By means of fuzzy logic, it is possible to find the solution to a given task from rules defined for analogous tasks. The calculation of fuzzy logics consists of three basic steps:

1. Fuzzification - transforms real variables into linguistic variables using their attributes. The variable usually has from three to seven attributes. The attribute and membership functions are defined for input and output variables. The degree of membership of attributes is expressed by a mathematical function - membership function ( $\Pi, \mathrm{Z}, \mathrm{S}$, etc.).

2. Fuzzy inference - defines the behaviour of a system by using rules of type <When>, <Then> on a linguistic level. Conditional clauses typically have the following form:

<When> [Input_a1 <And> Input_a2 <And $>\ldots$ $<$ And $>$ Input_an] < And > [Input_b1 <And> Input_b2 $<$ And $>$... $<$ And $>$ Input_bm] $<$ Then $>$ Output_1.

Each combination of attributes of input and output variables, occurring in condition <When>, <Then>, presents one rule. The rules are created by the user or expert himself.

3. Defuzzification - transfers the results of fuzzy inference (numerical values) on output variables by linguistic values. It describes results verbally (Paul, 2015).

\section{Research Methodology}

The research has been divided into three stages:

1) Input data identification and finding relations between input variables to client's creditworthiness.

2) Neuro-fuzzy model creation.

3) Neuro-fuzzy model verification and implementtation.

\section{Stage 1:}

The input data identification was based on non-adjusted input data on particular clients gained from an internal database of a particular insurance company and from external public databases ("Veřejny rejstřík a Sbírka listin Ministerstvo spravedlnosti Ceské republiky," 2015). In total, there were 66 data of real clients from South Bohemia Czech Republic (Doskocil, 2009). The obtained data were analysed, i.e. classified, adjusted and summarized. These adjusted data contained a basic set of the following variables: damages, insurance penetration, insurance length, share capital, earnings, $2^{\text {nd }}$ degree liquidity, legal form and indebtedness. These variables were statistically analysed with the aim to identify their relation to a client's creditworthiness. The process of finding the relations and their strength between two quantitative variables was executed using the correlation coefficient ( $\mathrm{Xu}, \mathrm{Ma}$, Zhou, Peng, \& Hou, 2016), and an independence test was carried out (Albert, Bouret, Fromont, \& Reynaud-Bouret, 2015) on the quantitative variables. Finding the relations between two qualitative variables was performed using contingency tables (Saigusa, Tahata, \& Tomizawa, 2015) and a chisquare test was carried out. At the moment of finding a relation between qualitative variables, its strength was evaluated by means of Cramer's contingence coefficient.

Stage 2:

The proposed neuro-fuzzy model was created by learning in the ANFIS Editor environment of the Fuzzy Logic Toolbox in the MATLAB software. The ANFIS Editor uses a fuzzy model of the Sugeno type. The artificial neural network is used as a tool for identifying fuzzy rules and setting the parameters of membership functions of the model variables.

The fundamental prerequisite for using the training and testing of the neuro-fuzzy model in the ANFIS editor is the existence of input and output data suitable for fuzzy modelling. The set consisted of the total of 66 records including input and output data concerning particular clients. Due to a follow-up testing of the neuro-fuzzy models, the aggregate data were divided, 33 records being used to determine neuro-fuzzy sub-models and 33 serving for testing neuro-fuzzy sub-models.

The input variables that had proven to be related to a client's creditworthiness were divided into two categories based on their nature. The first category consists of variables assessing insurance indicators. The second category comprises variables assessing accounting indicators. For this reason, the proposed neuro-fuzzy model consists of two sub-models: 1) Neuro-fuzzy sub-model for evaluating insurance indicators (DM_EII), 2) Neuro-fuzzy sub-model for evaluating accounting indicators (DM_EAI) and the complete model of a client's creditworthiness evaluation (DM_ECC).

The scheme of neuro-fuzzy model for evaluation of creditworthiness of the client is presented in Figure 1. 


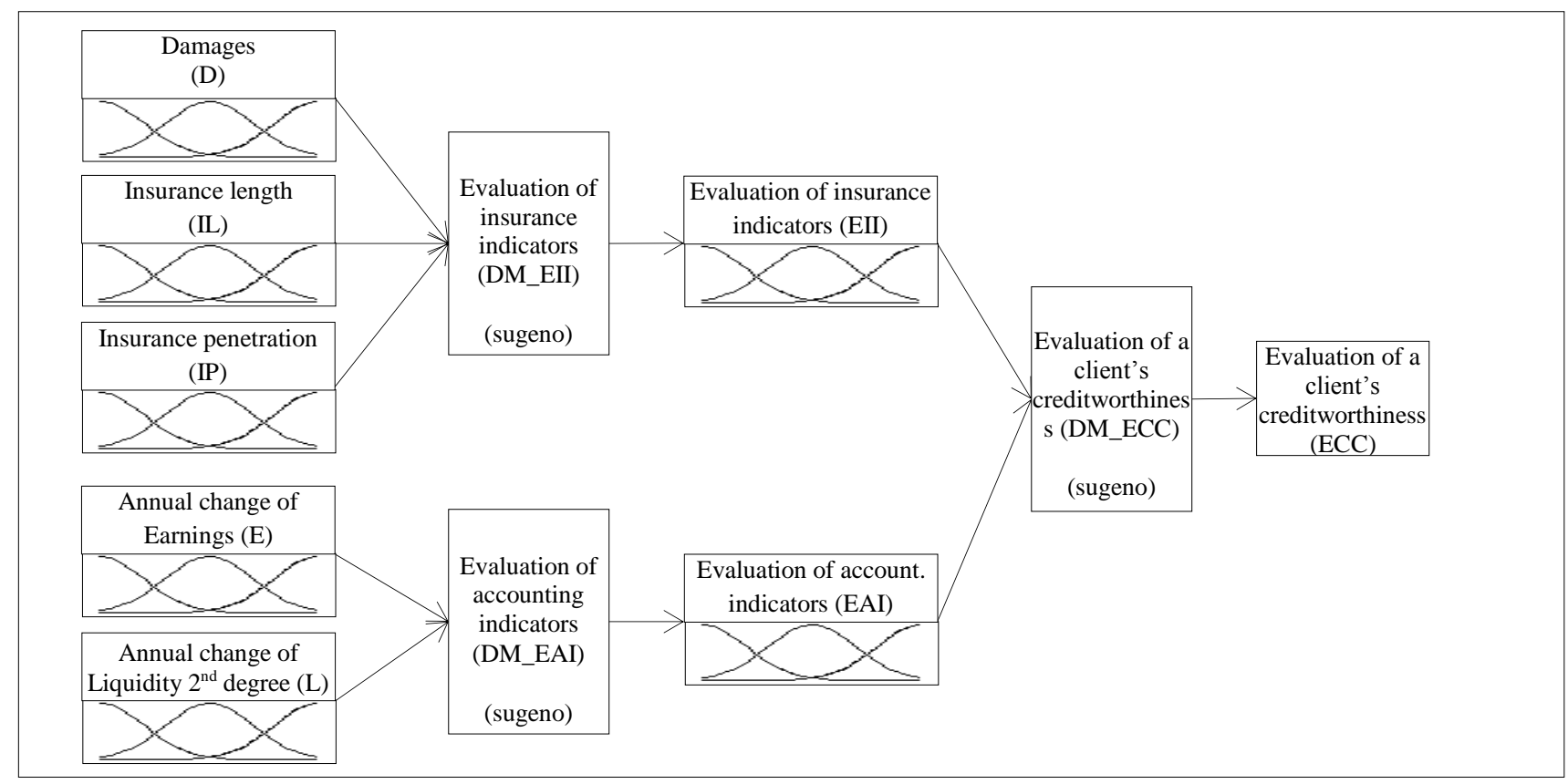

Figure 1. The Scheme of Neuro-Fuzzy Model for Evaluation of Creditworthiness of the Client

(Source: own processing)

\section{Phase 3:}

Model verification is based on the process of verifying model function from the perspective of entering input variables and evaluating the output variable, i.e. verification of identified fuzzy rules and parameters of membership functions.

The M-file (DM_ECC.m) was created for implementation of the model of client's creditworthiness in MATLAB software. The M-file serves as a connection between two partial sub-models (EII, EAI), to enter input values and automatic evaluation of client's creditworthiness in insurance.

\section{Results}

\section{Stage 1:}

The results of statistical data analysing showed that only the variables damages, insurance penetration, insurance length, earnings and $2^{\text {nd }}$ degree liquidity proved dependent on creditworthiness (see Table 1 and Table 2). These variables represent the inputs of the proposed neuro-fuzzy model of evaluating client's creditworthiness in insurance.

Summary Results - Independence Test of Quantitative Attributes

\begin{tabular}{|c|c|c|c|c|c|c|c|c|}
\hline \multirow{2}{*}{$\begin{array}{l}\text { Attribute X: } \\
\text { Attribute Y: }\end{array}$} & \multicolumn{3}{|c|}{ Test parameters } & \multicolumn{3}{|c|}{ Test result } & \multirow[b]{2}{*}{ Final test } & \multirow[b]{2}{*}{ Comment } \\
\hline & $\begin{array}{c}\text { Null } \\
\text { hypothesis }\end{array}$ & $\begin{array}{l}\text { Alternative } \\
\text { hypothesis }\end{array}$ & $\begin{array}{c}\text { Level of } \\
\text { significance } \alpha \\
\end{array}$ & Critical & region & $\begin{array}{l}\text { Critical } \\
\text { value }\end{array}$ & & \\
\hline $\begin{array}{l}\text { Creditworthiness } \\
\text { Damages }\end{array}$ & $\rho=0$ & $\rho \neq 0$ & 0.05 & -1.993 & 1.993 & 23.229 & $\begin{array}{l}\text { Rejection of } \\
\text { the null } \\
\text { hypothesis }\end{array}$ & $\begin{array}{l}\text { There is a linear dependence between } \\
\text { creditworthiness and damages. }\end{array}$ \\
\hline $\begin{array}{l}\text { Creditworthiness } \\
\text { Insurance penetration }\end{array}$ & $\rho=0$ & $\rho \neq 0$ & 0.05 & -1.993 & 1.993 & -2.196 & $\begin{array}{l}\text { Rejection of } \\
\text { the null } \\
\text { hypothesis }\end{array}$ & $\begin{array}{l}\text { There is a linear dependence between } \\
\text { creditworthiness and insurance } \\
\text { penetration. }\end{array}$ \\
\hline $\begin{array}{l}\text { Creditworthiness } \\
\text { Insurance length }\end{array}$ & $\rho=0$ & $\rho \neq 0$ & 0.05 & -1.993 & 1.993 & 3.484 & $\begin{array}{l}\text { Rejection of } \\
\text { the null } \\
\text { hypothesis }\end{array}$ & $\begin{array}{l}\text { There is a linear dependence between } \\
\text { creditworthiness and insurance length }\end{array}$ \\
\hline $\begin{array}{l}\text { Creditworthiness } \\
\text { Share capital }\end{array}$ & $\rho=0$ & $\rho \neq 0$ & 0.05 & -1.993 & 1.993 & -0.269 & $\begin{array}{l}\text { Acceptance } \\
\text { of the null } \\
\text { hypothesis }\end{array}$ & $\begin{array}{l}\text { There isn't a linear dependence } \\
\text { between creditworthiness and share } \\
\text { capital. }\end{array}$ \\
\hline
\end{tabular}


Summary Results - Independence Test of Qualitative Attributes (Chi-Square Test)

\begin{tabular}{|c|c|c|c|c|c|c|c|}
\hline \multirow[b]{2}{*}{$\begin{array}{l}\text { Attribute X: } \\
\text { Attribute Y: }\end{array}$} & \multicolumn{2}{|c|}{ Test parameters } & \multicolumn{3}{|c|}{ Test result } & \multirow[b]{2}{*}{ Final test } & \multirow[b]{2}{*}{ Comment } \\
\hline & Null hypothesis & $\begin{array}{l}\text { Level of } \\
\text { significance }\end{array}$ & $\begin{array}{l}\text { Critical } \\
\text { value } \\
\text { chi-square }\end{array}$ & $\begin{array}{l}\text { Critical } \\
\text { value chi- } \\
\text { square } \\
(r-1)(c-1)\end{array}$ & $\begin{array}{l}\text { Cramer's } \\
\text { contingency } \\
\text { coefficient }\end{array}$ & & \\
\hline $\begin{array}{l}\text { Creditworthiness Legal } \\
\text { form }\end{array}$ & $\begin{array}{l}\text { Attributes } \mathrm{X} \text { and } \mathrm{Y} \\
\text { are independent }\end{array}$ & 0.95 & 14.216 & 15.507 & 0.310 & $\begin{array}{l}\text { Acceptance } \\
\text { of the null } \\
\text { hypothesis } \\
\end{array}$ & $\begin{array}{l}\text { There isn't dependence } \\
\text { between creditworthiness and } \\
\text { legal form. }\end{array}$ \\
\hline $\begin{array}{l}\text { Creditworthiness } \\
\text { Earnings }\end{array}$ & $\begin{array}{l}\text { Attributes } \mathrm{X} \text { and } \mathrm{Y} \\
\text { are independent }\end{array}$ & 0.95 & 28.436 & 26.296 & 0.328 & $\begin{array}{l}\text { Rejection of } \\
\text { the null } \\
\text { hypothesis }\end{array}$ & $\begin{array}{l}\text { There is dependence between } \\
\text { creditworthiness and earnings. }\end{array}$ \\
\hline $\begin{array}{l}\text { Creditworthiness } \\
\text { Indebtedness }\end{array}$ & $\begin{array}{l}\text { Attributes } \mathrm{X} \text { and } \mathrm{Y} \\
\text { are independent }\end{array}$ & 0.95 & 10.341 & 21.026 & 0.229 & $\begin{array}{l}\text { Acceptance } \\
\text { of the null } \\
\text { hypothesis } \\
\end{array}$ & $\begin{array}{l}\text { There isn't dependence } \\
\text { between creditworthiness and } \\
\text { indebtedness. }\end{array}$ \\
\hline $\begin{array}{l}\text { Creditworthiness } \\
\text { Liquidity } 2^{\text {nd }} \text { degree }\end{array}$ & $\begin{array}{l}\text { Attributes } \mathrm{X} \text { and } \mathrm{Y} \\
\text { are independent }\end{array}$ & 0.95 & 35.933 & 26.296 & 0.369 & $\begin{array}{l}\text { Rejection of } \\
\text { the null } \\
\text { hypothesis }\end{array}$ & $\begin{array}{l}\text { There is dependence between } \\
\text { creditworthiness and liquidity } \\
2^{\text {nd }} \text { degree. }\end{array}$ \\
\hline
\end{tabular}

Source: own processing

The proposed model only uses the criteria of damages and insurance penetration from the traditional approach. The criterion of payment discipline has been replaced by more exact criteria of annual change in the economic output and an annual change in the 2 nd degree liquidity. Moreover, a new criterion of insurance length has been added, which has also been proven to be statistically dependent on a client's creditworthiness.

\section{Stage 2:}

The proposed neuro-fuzzy model consists of two submodels: 1) Neuro-fuzzy sub-model for evaluating insurance indicators (DM_EII), 2) Neuro-fuzzy sub-model for evaluating accounting indicators (DM_EAI) and the complete model of client's creditworthiness evaluation (DM_ECC).

The neuro-fuzzy model for evaluating total creditworthiness of a client (DM_ECC) has got two input variables (EII, EAI), one rule block and one output variable (ECC - evaluation of creditworthiness of the client). The input variables EII and EAI have got three attributes: F fail, $\mathrm{G}$ - good, E- excellent. A membership function of type gaussmf was used.

1) Neuro-fuzzy sub-model for evaluating insurance indicators (DM_EII) - model creation

The neuro-fuzzy sub-model for evaluating insurance indicators (DM_EII) has got three input variables (D damages, IL - insurance length, IP - insurance penetration), one rule block and one output variable (EII - evaluation of insurance indicators). The input variables D, IL and IP have got three attributes: $\mathrm{S}$ - small, $\mathrm{M}$ - medium, L - large. A membership function of type gaussmf was used (Lai, 2006).

To generate the FIS (Fuzzy Inference System) structure, the Grid Partition method was selected, gaussmf relevance function, number of functions [ [ $\left.\begin{array}{lll}3 & 3 & 3\end{array}\right]$ and constant type of output function EII.

For the purpose of the DM_EII neuro-fuzzy model training, a separate file DM_EII_training.txt was created, containing the input training data (33 records). The hybrid optimization method was selected for the process of training the artificial neural network; it combines the method of error back-propagation with the least squares method for greater learning accuracy with zero error tolerance. The number of epochs was edited to 50 . The process of error minimization in testing (training error) is presented in Figure 2 on the left. The structure of the neural network is presented in Figure 2 on the right.

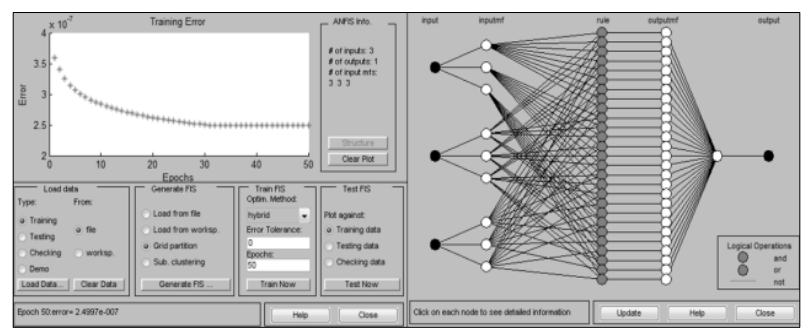

Figure 2. ANFIS Editor - Training Error and Structure of Neural Network

(Source: own processing)

A separate file DM_EII_testing.txt was created for the purpose of testing this sub-model (33 records).

The ANFIS Editor generated parameters for the neurofuzzy sub-model (DM_EII): parameters of membership functions, fuzzy rules, output variable. These parameters are set above the input data for each variable (DM_EII_training.txt). The identified parameters can be viewed or edited in the respective FIS Editor. The value range is defined within the interval $\langle 0 \div 1\rangle$. The parameters of the DM_EII neuro-fuzzy sub-model are presented in the following Figure 3.

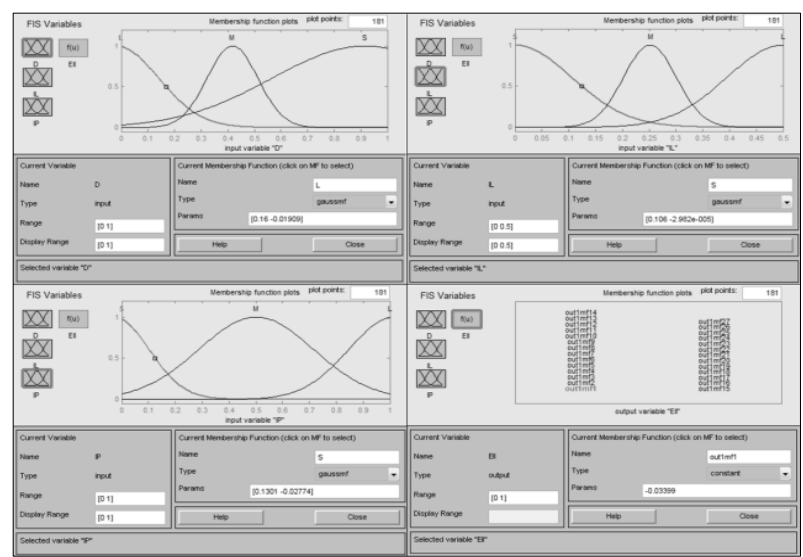

Figure 3. Parameters of Membership Function - DM_EII (Source: own processing) 
27 rules were established for the DM_EII neuro-fuzzy model. Based on the relevance of input values to membership functions, the respective output constant function is assigned to the output.

Figure 4 shows the correlation between inputs and output. Specifically, this image shows graphically the graphical correlation between two input variables D and IP and one output variable EII. It is a function dependence EII $=\mathrm{f}(\mathrm{D}, \mathrm{IL}, \mathrm{IP})$, where the input variable IL in this threedimensional graph is a constant with a value of 0 . The user can change this variable for presentation in graphs.

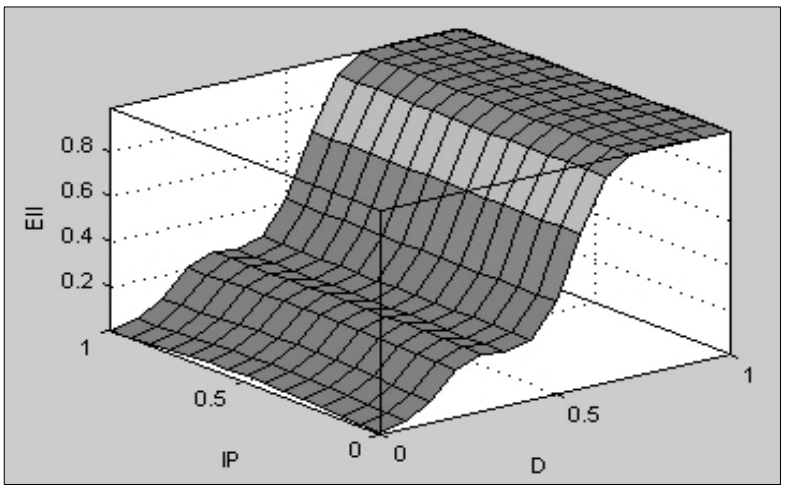

Figure 4. Correlation between Variables

(Source: own processing)

The point with the coordinates $[0 ; 0 ; 0]$ represents a situation where the input variable $\mathrm{D}$ is evaluated as large and the input variable IP is evaluated as small, than the output variable EII is evaluated as fail. The point with the coordinates $[1 ; 1 ; 1]$ represents a situation where the input variable $\mathrm{D}$ is evaluated as small and the input variable IP is evaluated as large, than the output variable EII is evaluated as excellent.

Graphical representation of input-output dependence enables the set parameters of the fuzzy model to be checked. Generally speaking, the displayed area of the given model is suitable as the set rules and selected membership functions make the model sufficiently general.

2) Neuro-fuzzy sub-model for evaluating of accounting indicators (DM_EAI) - model creation

The neuro-fuzzy sub-model for evaluating accounting indicators (DM_EAI) has got two input variables (E earnings, $\mathrm{L}-$ liquidity $2^{\text {nd }}$ degree), one rule block and one output variable (EAI - evaluation of accounting indicators). The input variables $\mathrm{E}$ and $\mathrm{L}$ have got three attributes: $\mathrm{D}$ drop, $\mathrm{S}$ - stagnation, $\mathrm{G}$ - growth. A membership function of type gaussmf was used.

To generate the FIS (Fuzzy Inference System) structure, the Grid Partition method was selected, gaussmf relevance function, number of functions [ [ $\left.\begin{array}{lll}3 & 3 & 3\end{array}\right]$ and constant type of output function EAI.

A separate file DM_EAI_training.txt was created for the purpose of training the DM_EAI neuro-fuzzy sub-model, containing the input data aimed at training (33 records).

The hybrid optimization method was selected for the process of training the artificial neural network; it combines the method of error back-propagation with the least squares method for greater learning accuracy with zero error tolerance. The number of epochs was edited to 50 .
The process of error minimization in testing (training error) is presented in Figure 5 on the left left. The structure of the neural network is presented in Figure 5 on the right.

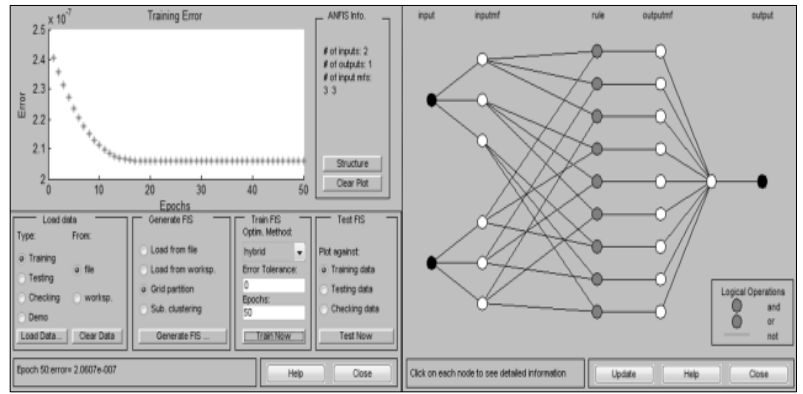

Figure 5. ANFIS Editor - Training Error and Structure of Neural Network

(Source: own processing)

A separate file $D M \_E A I$ testing.txt was created for the purpose of testing this sub-model (33 records).

The ANFIS Editor generated parameters for the neurofuzzy sub-model (DM_EAI): parameters of membership functions, fuzzy rules, output variable. These parameters are set above the input data for each variable (DM_EAI_training.txt). The identified parameters can be viewed or edited in the respective FIS Editor. The value range is defined within the interval $\langle 0 \div 1\rangle$. The parameters of the DM_EAI neuro-fuzzy sub-model are presented in the following Figure 6.

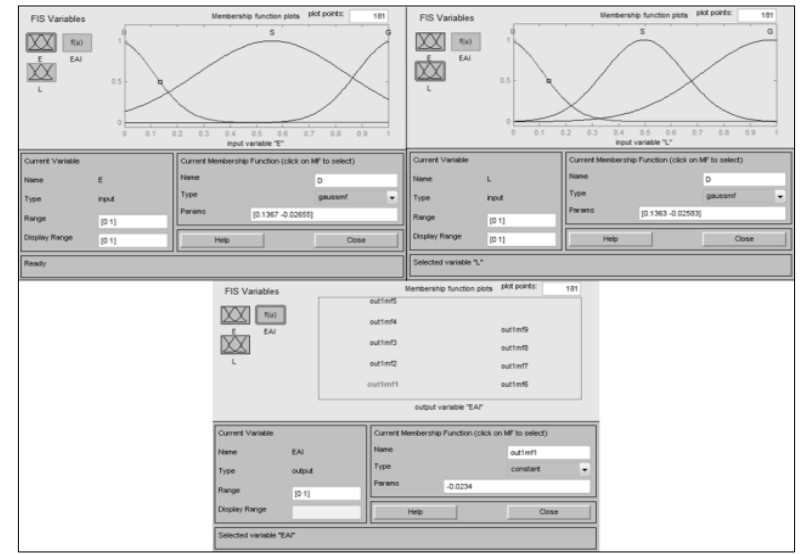

Figure 6. Parameters of membership function - DM_EAI

(Source: own processing)

9 rules were established for the DM_EAI neuro-fuzzy model. Based on the relevance of input values to membership functions the respective output constant function is assigned to the output.

Figure 7 shows the correlation between inputs and output. Specifically, this image shows graphically the graphical correlation between two input variables $\mathrm{E}$ and $\mathrm{L}$ and one output variable EAI. It is a function dependence $\mathrm{EAI}=\mathrm{f}(\mathrm{E}, \mathrm{L})$. 


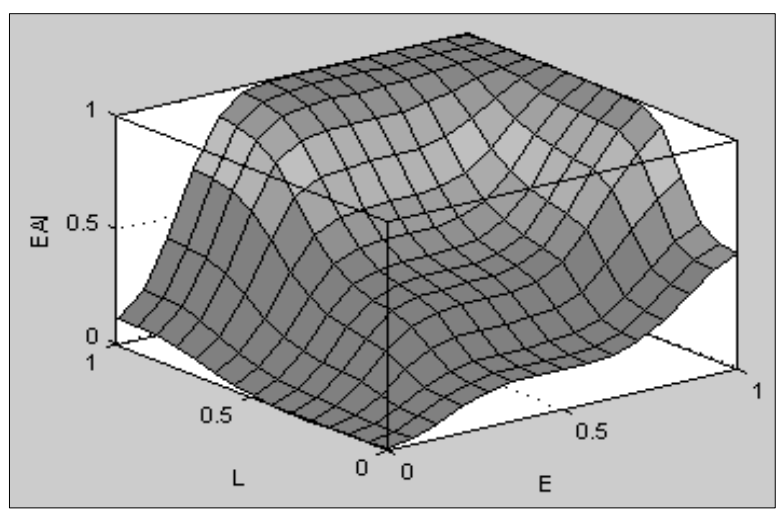

Figure 7. Correlation between variables

(Source: own processing)

The point with the coordinates $[0 ; 0]$ represents a situation where the input variables $\mathrm{E}$ and $\mathrm{L}$ are evaluated as decreasing, than the output variable EAI is evaluated as fail. The point with the coordinates $[1 ; 1]$ represents a situation where the input variables $\mathrm{E}$ and $\mathrm{L}$ are evaluated as increasing, than the output variable EAI is evaluated as excellent.

Graphical representation of input-output dependence enables the set parameters of the fuzzy model to be checked. Generally speaking, the displayed area of the given model is suitable as the set rules and selected membership functions make the model sufficiently general.

\section{Phase 3:}

1) Neuro-fuzzy sub-model for evaluating insurance indicators (DM_EII) - model verification

Sub-model verification DM_EII was performed using real client data (DM_EII_testing.txt). Figure 8 shows the evaluation of insurance indicators (EII) of concrete clients. The input variables of one concrete client are set up as $\mathrm{D}=$ $1, \mathrm{IL}=1, \mathrm{IP}=1$. It leads to the result (output) $\mathrm{EII}=1$ which means that the EII is evaluated as excellent. It was used the last rule. See Figure 8, left. The input variables of next concrete client are set up $\mathrm{D}=0, \mathrm{IL}=0, \mathrm{IP}=0$. It leads to the result (output) EII $=0$ which means that the EII is evaluated as fail. It was used the first rule. See Figure 8, right.

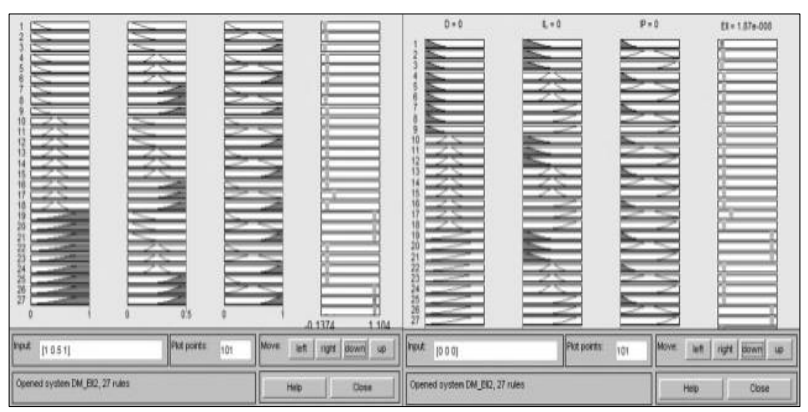

Figure 8. Verification of neuro-fuzzy sub-model DM_EII (Source: own processing)

The model was verified by use of input data in the same way. The results acquired corresponded to the requirement, therefore the model can generally be considered functional.

2) Neuro-fuzzy sub-model for evaluating of accounting indicators (DM_EAI) - model verification
Sub-model verification DM_EAI was performed using real client data (DM_EAI_testing.txt).

Figure 9 shows the evaluation of insurance indicators (EAI) of concrete clients. The input variables of one concrete client are set up $\mathrm{E}=1$ and $\mathrm{L}=1$. It leads to the result (output) $\mathrm{EAI}=1$, which means that the EAI is evaluated as excellent. The last rule was used. See Figure 9, left. The input variables of next concrete client are set up E $=0$ and $\mathrm{L}=0$. It leads to the result (output) $\mathrm{EAI}=0$, which means that the EAI is evaluated as fail. The first rule was used. See Figure 9, right.

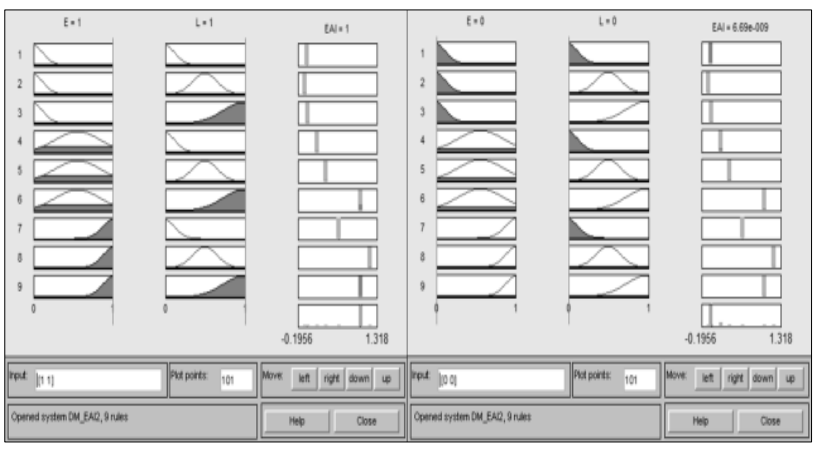

Figure 9. Verification of neuro-fuzzy sub-model DM_EAI

$$
\text { (Source: own processing) }
$$

The M-file (DM_ECC.m) was created for implementation of the neuro-fuzzy model in MATLAB software. The M-file contains the following command sequence:

1 - clear all

2 - EII = readfis('DM_EII.fis');

3 - DataEII = input('Inputs [D; IL; IP]: ');

4 - EvaluationEII = evalfis(DataEII, EII);

5 - EAI = readfis('DM_EAI.fis');

6 - DataEAI = input('Inputs [E; L]: ');

7 - EvaluationEAI = evalfis(DataEAI, EAI);

8 - ECC = readfis('DM_ECC.fis');

9 - $\mathrm{A}(1)=$ EvaluationEII;

$10-\mathrm{A}(2)=$ EvaluationEAI;

11 - EvaluationECC = evalfis $(\mathrm{A}, \mathrm{ECC})$;

12 - if EvaluationECC $<0.333$ 'Creditworthiness of the client is fail'

13 - elseif EvaluationECC $<0.666$ 'Creditworthiness of the Client is good'

14 - else 'Creditworthiness of the Client is excellent'

15 - end

16 - fuzzy(ECC)

17 - mfedit(ECC)

18 - ruleedit(ECC)

19 - surfview(ECC)

20 - ruleview(ECC)

If the simulation in the MATLAB environment uses an M-file titled DM_ECC.m, the request to enter inputs [D; IL; $\mathrm{IP}]$ and $[\mathrm{E} ; \mathrm{L}]$ is gradually recorded on the display. After entering the input values, e.g. $\mathrm{D}=0, \mathrm{IL}=0 ; \mathrm{IP}=0$ in the form $[0 ; 0 ; 0]$ and inputs $\mathrm{E}=0, \mathrm{~L}=0$ in the form $[0 ; 0]$ the result is $\mathrm{ECC}=$ Creditworthiness of the Client is fail. See Figure 10. 


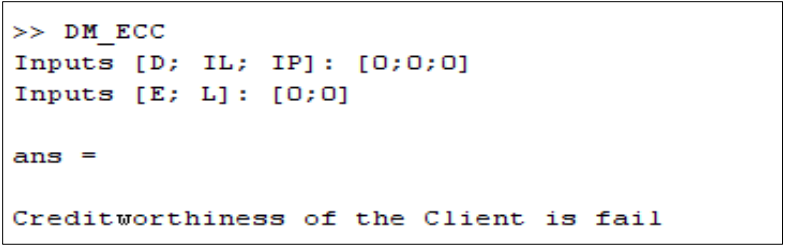

Figure 10. Creditworthiness - fail (Source: own processing)

After entering the input values, e.g. $\mathrm{D}=1, \mathrm{IL}=1$; IP $=$ 1 in the form $[1 ; 1 ; 1]$ and inputs $E=1, L=1$ in the form $[1 ; 1]$ the result is $\mathrm{ECC}=$ Creditworthiness of the Client is excellent. See Figure 11.

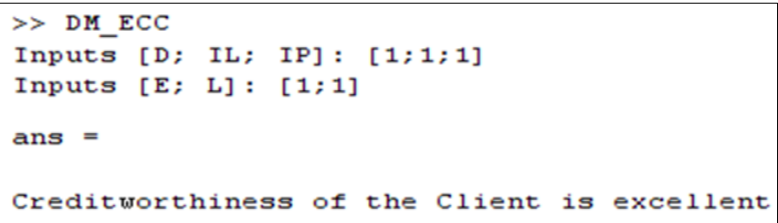

Figure 11. Creditworthiness - excellent (Source: own processing)

\section{Discussion}

The proposed evaluation model is realized by means of abstract modelling when the system structure is modelled. The fuzzy approach was chosen mainly due to the ability of fuzzy sets to work with inaccurate (vague) notions. These notions are used in evaluating a client's creditworthiness. Defining exact mathematical relations that would sufficiently and credibly model the given reality would be considerably complicated in this decision-making issue.

The model was set above input data (DM_EII_training.txt, DM_EAI_training.txt). These data formed the basis for the description of the modeled system from the perspective of purpose and objectives. A combined system in the form of a neuro-fuzzy system (artificial neural network - fuzzy logic) was used to identify the rules and set the parameters of membership functions. The neuro-fuzzy model contains only such input variables that have been proven to be related to a client's creditworthiness. The constructed model was verified and tested using testing data (DM_EII_testing.txt, DM_EAI_testing.txt). The results obtained corresponded to the requirement, therefore the model can generally be considered functional. After verification, the model can be applied in real operation as a tool for support of decision-making in evaluating client's creditworthiness in insurance industry.

The success of the evaluation model and its limitations are generally related mostly to the size and quality of the input data set (training, testing and control data). This phase becomes dominant in the modelling process. In the event of identifying other or new data it is possible to find other or further potential relations, or to make these relations more accurate, thus making the rules and shapes of membership functions more precise. It is always necessary to respect the lifespan of the model, which decreases in time. The model has to be upgraded, i.e. any found deviations from reality need to be corrected or a completely new model has to be created.

The proposed model differs from the current approaches primarily thanks to its complex, systematic and hierarchical ability to evaluate the new identified factors related to a client's creditworthiness as fuzzy variables. This is its important contribution. The fuzzy approach minimises a lack of exact calculation approach. The advantage of fuzzy sets is the ability to work with vague concepts, i.e. with experts' knowledge. These concepts are widely used in everyday insurance industry practice. The next contribution is the possibility of further experimentation with the model in the form of simulation. This way, further information and knowledge about the issue can be identified. These can be used as a support for a decision-making in strategic management of the insurance companies e.g. in the marketing activities (Hsieh, Liu, \& Tzeng, 2014). Thanks to the model it is possible to automate and accelerate the process of evaluation of a client's creditworthiness in the insurance industry too.

\section{Conclusion}

The article deals with the issue of a client's creditworthiness evaluation in the insurance industry. The factors which have relations to a client's creditworthiness were identified in the first phase of the research. These factors represent the inputs of the proposed model. The evaluation model of a client's creditworthiness was created in the second phase. In the third phase, the model was verified and implemented. The neuro-fuzzy method was used for creating, verification and implementation of the model. Five variables are selected as the inputs including damages, insurance length, insurance penetration, annual earnings and the $2^{\text {nd }}$ degree liquidity. These input variables were divided into two categories based on their nature. The first category comprises variables assessing insurance indicators (damages, insurance length, and insurance penetration). The second category comprises variables assessing accounting indicators (annual earnings and $2^{\text {nd }}$ degree liquidity). For this reason, the proposed neuro-fuzzy model consists of two sub-models (DM_EII, DM_EAI) and the complete neuro-fuzzy model DM_ECC.

The main contribution of the paper is the identification of new factors which have relation to a client's creditworthiness and the creation of the evaluation model which works with these identified factors transferred to fuzzy variables. The proposed model differs from the current approaches primarily thanks to its complex, systematic and hierarchical ability to evaluate the key factors as fuzzy variables. Thanks to the model, it is possible to automate and accelerate the process of evaluation of a client's creditworthiness in the insurance industry. The knowledge gained from the evaluation model can be immediately incorporated in the strategic management of insurance companies e.g. in marketing activities.

\section{Acknowledgments}

This paper was supported by grant FP-S-15-2787 "Effective Use of ICT and Quantitative Methods for Business Processes Optimization" from the Internal Grant Agency at Brno University of Technology. 


\section{References}

Albert, M., Bouret, Y., Fromont, M., \& Reynaud-Bouret, P. (2015). Bootstrap and Permutation Tests of Independence for Point Processes. Annals of Statistics, 43(6), 2537-2564. http://doi.org/10.1214/15-AOS1351

Alhassan, A. L., \& Biekpe, N. (2015). Efficiency, Productivity and Returns to Scale Economies in the Non-Life Insurance Market in South Africa. Geneva Papers on Risk and Insurance-Issues and Practice, 40(3), 493515. http://doi.org/10.1057/gpp.2014.37

Armeanu, D., Istudor, N., Florinel, S. M., \& Burca, A.-M. (2014). Analysis of the Romanian Insurance Market Based on Ensuring and Exercising Consumers' Right to Claim. Amfiteatru Economic, 16(36), 550-562.

Ayesh, A., \& Blewitt, W. (2015). Models for Computational Emotions from Psychological Theories Using TypeII Fuzzy Logic. Cognitive Computation, 7(3), 309-332. http://doi.org/10.1007/s12559-014-9286-8

Berry-Stoelzle, T. R., Hoyt, R. E., \& Wende, S. (2013). Capital Market Development, Competition, Property Rights, and the Value of Insurer Product-Line Diversification: A Cross-Country Analysis. Journal of Risk and Insurance, 80(2), 423-459. http://doi.org/10.1111/j.1539-6975.2012.01470.x

Bertola, G., \& Koeniger, W. (2015). Hidden insurance in a moral-hazard economy. Rand Journal of Economics, 46(4), 777-790. http://doi.org/10.1111/1756-2171.12110

Biener, C., Eling, M., \& Wirfs, J. H. (2016). The determinants of efficiency and productivity in the Swiss insurance industry. European Journal of Operational Research, 248(2), 703-714. http://doi.org/10.1016/j. ejor.2015.07.055

Brockett, P. L., Cooper, W. W., Golden, L. L., \& Xia, X. (1997). A case study in applying neural networks to predicting insolvency for property and casualty insurers. Journal of the Operational Research Society, 48(12), 1153-1162. https://doi.org/10.1057/palgrave.jors.2600461

Brockett, P. L., Golden, L. L., Jang, J., \& Yang, C. (2006). A comparison of neural network, statistical methods, and variable choice for life insurers' financial distress prediction. Journal of Risk and Insurance, 73(3), 397419. http://doi.org/10.1111/j.1539-6975.2006.00181.x

Chiet, N. S., Jaaman, S. H., Ismail, N., \& Shamsuddin, S. M. (2009). Insolvency Prediction Model Using Artificial Neural Network for Malaysian General Insurers. In A. Abraham, F. Herrera, A. Carvalho, \& V. Pai (Eds.), 2009 World Congress on Nature \& Biologically Inspired Computing (nabic 2009) (pp. 583-588). New York: Ieee. https://doi.org/10.1109/nabic.2009.5393413

Doskocil, R. (2009). Metodika zjist'ování bonity klienta v pojist'ovnictví. Available from Internet: http://www.vutium.vutbr.cz/tituly/pdf/ukazka/978-80-214-3902-3.pdf

Doskocil, R., \& Doubravský, K. (2014). Decision-making rules based on rough set theory: Creditworthiness case study. In Crafting Global Competitive Economies: 2020 Vision Strategic Planning \& Smart Implementation. International Business Information Management Association (IBIMA), 321-327, Milan, Italy.

Doskocil, R., \& Doubravský, K. (2015). Identifying of Profitability of the Client under Condition of Uncertainty. In Innovation Vision 2020: From Regional Development Sustainability to Global Economic Growth.: International Business Information Management Association (IBIMA), 2587-2595, Amsterdam, Netherlands.

Doubravský, K., \& Doskocil, R. (2016). Determination of Client Profitability under Uncertainty Based on Decision Tree. Journal of Eastern Europe Research in Business \& Economics, 1-8. doi: 10.5171/ 2016.445849

Eling, M., \& Schmit, J. T. (2012). Is There Market Discipline in the European Insurance Industry? An Analysis of the German Insurance Market. Geneva Risk and Insurance Review, 37(2), 180-207. http://doi.org/10.1057/grir.2011.8

Gocic, M., Motamedi, S., Shamshirband, S., Petkovic, D., \& Hashim, R. (2015). Potential of adaptive neurofuzzy inference system for evaluation of drought indices. Stochastic Environmental Research and Risk Assessment, 29(8), 1993-2002. http://doi.org/10.1007/s00477-015-1056-y

Hendrych, R., \& Cipra, T. (2015). Econometric Model of the Czech Life Insurance Market. Prague Economic Papers, 24(2), 173-191. https://doi.org/10.18267/j.pep.507

Hsieh, S.-H., Liu, C.-T., \& Tzeng, L. Y. (2014). Insurance Marketing Channel as a Screening Mechanism: Empirical Evidences from Taiwan Automobile Insurance Market. Geneva Papers on Risk and InsuranceIssues and Practice, 39(1), 90-103. http://doi.org/10.1057/gpp.2012.52 
Kwon, W. J. (2014). Human Capital Risk and Talent Management Issues in the Insurance Market: Public Policy, Industry and Collegiate Education Perspectives. Geneva Papers on Risk and Insurance-Issues and Practice, 39(1), 173-196. http://doi.org/10.1057/gpp.2013.11

Lai, L.-H. (2006). Underwriting profit margin of P/L insurance in the fuzzy-ICAPM. Geneva Risk and Insurance Review, 31(1), 23-34. http://doi.org/10.1007/s10713-006-9465-y

Ma, Y. F. (2015). Efficiency Analysis on Business Model of Construction Accidental Injury Insurance in China. International Conference on Advances in Management Engineering and Information Technology (ameit 2015), 425-431.

Nikolic, V., Petkovic, D., Yee, P. L., Shamshirband, S., Zamani, M., Cojbasic, Z., \& Motamedi, S. (2016). Potential of neuro-fuzzy methodology to estimate noise level of wind turbines. Mechanical Systems and Signal Processing, 66-67, 715-722. http://doi.org/10.1016/j.ymssp.2015.05.005

Palavar, O., Ozyurek, D., \& Kalyon, A. (2015). Artificial neural network prediction of aging effects on the wear behavior of IN706 superalloy. Materials \& Design, 82, 164-172. http://doi.org/10.1016/j.mat des.2015.05.055

Paul, S. K. (2015). Supplier selection for managing supply risks in supply chain: a fuzzy approach. International Journal of Advanced Manufacturing Technology, 79(1-4), 657-664. http://doi.org/10.1007/s00170-015-6867-y

Saigusa, Y., Tahata, K., \& Tomizawa, S. (2015). Orthogonal decomposition of symmetry model using the ordinal quasi-symmetry model based on f-divergence for square contingency tables. Statistics \& Probability Letters, 101, 33-37. http://doi.org/10.1016/j.spl.2015.02.023

Shuang, P., \& Wei, L. (2011). The Early Warning of Life Insurance Company Based on BP Artificial Neural Network. In Y. W. Wu (Ed.), Computing and Intelligent Systems, Pt Iii (Vol. 233, pp. 30-38). Berlin: Springer-Verlag Berlin. https://doi.org/10.1007/978-3-642-24010-2_5

Stepchenko, D., \& Voronova, I. (2015). Assessment of Risk Function Using Analytical Network Process. Inzinerine Ekonomika-Engineering Economics, 26(3), 264-271. http://doi.org/10.5755/j01.ee.26.3.8736

Ulbinaite, A., Kucinskiene, M., \& Le Moullec, Y. (2013). Determinants of Insurance Purchase Decision Making in Lithuania. Inzinerine Ekonomika-Engineering Economics, 24(2), 144-159. http://doi.org/10.5755/j01. ee.2.24.2.3439

Veřejný rejstř́ík a Sbírka listin - Ministerstvo spravedlnosti Ceské republiky. (2015). Available from Internet: https://or.justice.cz/ias/ui/rejstrik

Witkowska, J., \& Lakstutiene, A. (2014). Social Insurance Service Quality Surveys as a Customer Orientation Strategy. Inzinerine Ekonomika-Engineering Economics, 25(1), 103-111. http://doi.org/10.5755/j01.ee. 25.1.5115

Wu, D., Olson, D. L., \& Dolgui, A. (2015). Decision making in enterprise risk management: A review and introduction to special issue. Omega-International Journal of Management Science, 57, 1-4. http://doi.org/10.1016/j.omega.2015.04.011

Xuan, L., Meng, Y., \& Dongli, G. (2010). Applications of the Risk Management to Forestry Systems Engineering in China-Literature Analysis for the Forestry Project Risk Management. (K. L. Zhu \& H. Zhang, Eds.). Marrickville: Aussino Acad Publ House.

Xu, W., Ma, R., Zhou, Y., Peng, S., \& Hou, Y. (2016). Asymptotic properties of Pearson's rank-variate correlation coefficient in bivariate normal model. Signal Processing, 119, 190-202. http://doi.org/10.1016/j.sigpro.2015.08.010

Zadeh, L. A. (1965). Fuzzy sets. Information and Control, 8(3), 338-353. http://doi.org/10.1016/S00199958(65)90241-X

Zadeh, L. A. (2007). Fuzzy logic as the logic of natural languages. In P. Melin, O. Castillo, E. G. Ramirez, J. Kacprzyk, \& W. Pedrycz (Eds.), Analysis and Design of Intelligent Systems Using Soft Computing Techniques , 41, 1-2. Berlin: Springer-Verlag Berlin. https://doi.org/10.1007/978-3-540-72432-2_1

The article has been reviewed.

Received in February, 2016; accepted in February, 2017. 